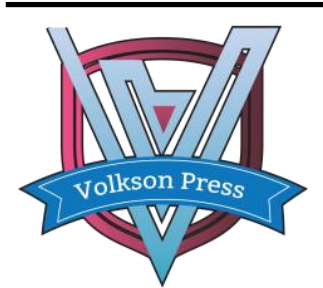

Contents List available at VOLKSON PRESS

Engineering \& Technology Innovations (ETI)

DOI : http://doi.org/10.26480/iceti.01.2017.63.67

\title{
MAPPING SOLAR RADIATION AT DIFFERENT TIMESCALES USING BOTH SUNSHINE DURATION AND DIURNAL TEMPERATURE RANGE IN CHINA
}

\author{
Sidong Zeng1, Hong Du2, , Hui Wan', Jinfeng Huang1 \\ 1 Changjiang Institute of Survey, Planning, Design and Research, Wuhan 430010, China \\ 2 South-Central University for Nationalities, Wuhan 430074, China, *Corresponding author: amydh2005@163.com
}

This is an open access article distributed under the Creative Commons Attribution License, which permits unrestricted use, distribution, and reproduction in anv medium, provided the original work is properly cited

\section{ARTICLE DETAILS}

\section{Article History:}

Received 02 october 2017 Accepted 06 october 2017 Available online 11 october 2017

\section{Keywords:}

Solar radiation; ÅngströmPrescott; Hargreaves-Samani; Bristow-Campbell; China.

\section{ABSTRACT}

Previous studies investigating on the spatiotemporal variation of solar radiation are mainly focus on the annual changes, while higher time resolution spatiotemporal distributions are limited, which will be more important for different biogeochemical and hydrological processes with different timescales. In this paper, the spatiotemporal distribution of solar radiation at annual and seasonal timescales are mapped in China based on three widely used models including the Ångström-Prescott, Hargreaves-Samani and Bristow-Campbell models. Results show that the annual solar radiation decreases significantly in the Eastern monsoon zone and the Northwestern arid zone. The seasonal solar radiation decreases in most of the season in the Northwestern arid zone and the decrease trends are significantly in spring and autumn in the Eastern monsoon zone, while the changing trends are not significant in most of the seasons in the Tibetan Plateau frigid zone. Moreover, "From diming to brightening" occurs in winter, annual and particularly in spring radiation changes, while in summer solar radiation shows a continuous decrease trend and a slight decrease trend is detected in autumn solar radiation.

\section{INTRODUCTION}

Global solar radiation is the primary energy source for life and the driving factor for physical, chemical and biological processes on the earth [1]. The spatiotemporal variation of solar radiation may substantially affect many parts in earth systems such as surface temperature, evapotranspiration, photosynthesis, energy transfer, vegetation growth and phenology and even solar energy utilization. Hence, it's important to investigate the spatial and temporal pattern of solar radiation at global and regional scales. However, lack of solar radiation observations at large areas is a persistent problem in related studies on solar radiation [2].

In order to meet the requirements of solar radiation data for different studies, several methods are used to estimate solar radiation including mechanism model [3], satellite-derived method [4], stochastic algorithm [5], empirical model [6] and learning machine method [7]. Among these methods, the empirical model using observed meteorological data is attractive for the good performances and data availability [8]. ÅngströmPrescott (A-P) model [9] based on sunshine duration, Hargreaves-Samani (H-S) model (1982) [6] and Bristow-Campbell (B-C) model (1984) [10] based on diurnal temperature ranges are three simple but useful empirical models that have been widely used to estimate solar radiation in many regions around the world. To estimate more accuracy solar radiation, the parameters in the empirical models are often calibrated before its application. Moreover, these empirical models are often modified for better performances. For example, the A-P model has been modified by adding more climate variables into the original equation [11] or changing the order of the relative sunshine duration [12]. However, some studies show that those modifications are not always showing any advantages comparing to the original equation $[13,14]$. The H-S model proposed by Hargreaves and Samani has also been modified with different equations in various places but the improvements of those modifications are various from different regions [8] and the modified versions sometimes even perform worse [15]. Therefore, calibration of the parameters in the original model is still a useful method for good precision comparing to modification of the current models.

Sustained declines in solar radiation during about 1960-1990 and then an increase in solar radiation since 1990s have been reported in many places around the world based on both station observations and satellites [16]. The similar changes have also been detected in China. Xia et al. (2006) [17] reports that solar radiation reduces significantly from 1961 to 1990 but a pronounced increase trend has been detected from 1984-2000. Ye et al. (2010) [2] shows that the annual trend of solar radiation is $-0.074 \mathrm{MJm}$. ${ }^{2}$ year-1 during 1961-1989 and then increases slightly by $0.0054 \mathrm{MJm}^{-2}$ year ${ }^{1}$ using measured solar radiation at 43 sites. Tang et al. (2011) [18] shows that the changing trend is about $-0.23 \mathrm{Wm}^{-2}$ year $^{-1}$ during $1961-2000$ for the whole China with quality-controlled data. Most of the previous studies are mainly conducted on the annual changes of solar radiation, while few studies focus on the seasonal changes, which is especially important for the earth systems. For example, Pohl et al. (2012) [19] showed that a 10\% changes in spring solar radiation will result in a snowmelt equal to the overall mean end-of-winter snow water in the research region in Canada. Moreover, seasonal solar radiation changes have more impact on natural system than annual changes due to seasonal behaviors of vegetation growth, evapotranspiration and then surface water available.

The purpose of this study aims to map the spatial and temporal distributions of annual and seasonal solar radiation based on calibrated empirical models in China. Moreover, comparisons of the spatiotemporal distribution of solar radiation at different timescales based on three models including the A-P, H-S and B-C models are conducted. The three models are calibrated using the measured solar radiation at 94 sites and then the parameters are extended to 756 meteorological stations to map the spatial and temporal distributions of solar radiation in China. This paper is arranged as follows: Section 2 describes the materials and methods including model description and calibration and trend analysis method. Section 3 provides the results and discussions respectively and conclusions are summarized in Section 4.

\section{Materials and methods}

\subsection{Sites and dataset}

In this study, daily observed records including sunshine duration, maximum and minimum daily temperature at 756 meteorological sites in China from the National Climate Centre (NCC) of China Meteorological Administration (CMA) were used, among which 94 sites have solar radiation observation. The location and distribution of the meteorological stations in different agro-climatic zones including the Eastern monsoon (EM), Northwestern arid (NA) and Tibetan Plateau frigid (TP) zones are shown in Figure 1. 


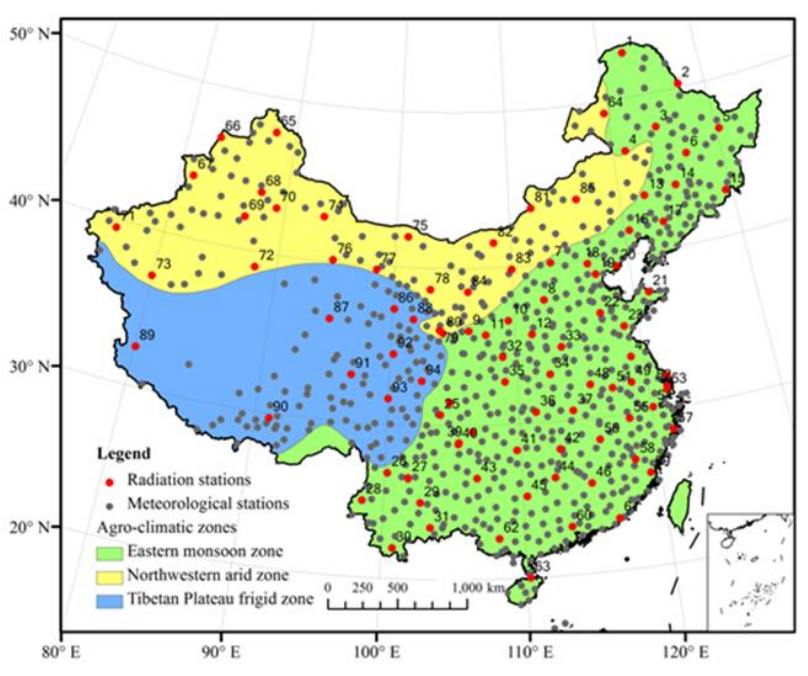

Figure 1. The spatial distribution of the 756 meteorological stations (the black circles) and the 94 stations (the red circles with the ID label) which have observed solar radiation data in different agro-climatic zones in China.

\subsection{Methods}

\subsubsection{Extraterrestrial radiation for daily periods}

The amount of solar radiation reaching a horizontal surface is mainly depended on the radiation received at the top of earth's atmosphere which is called extraterrestrial radiation. To estimate the daily solar radiation, it's necessary to calculate the daily extraterrestrial radiation firstly. The extraterrestrial radiation for daily periods $R_{a}\left(\mathrm{MJ} \mathrm{m}^{-2}\right.$ day-1) can be estimated following the equation provided by the Food and Agriculture Organization (FAO):

$$
R_{a}=1440 \cdot G_{s c} d_{r}\left[\omega_{s} \sin (\varphi) \sin (\delta)+\cos (\varphi) \cos (\delta) \sin \left(\omega_{s}\right)\right] / \pi
$$

Where $G_{s c}$ is solar constant, $d_{r}$ is inverse relative distance Earth-Sun, $\omega_{s}$ is sunset hour angle (rad), $\varphi$ is latitude (rad), $\delta$ is solar decimation (rad) of the station.

\subsection{2 Ångström-Prescott model}

The Ångström-Prescott model, which relates solar radiation to extraterrestrial radiation and relative sunshine duration, has been widely used in different areas around the world and performs very well. The solar radiation $R_{s}\left(\mathrm{MJ} \mathrm{m}^{-2}\right.$ day $\left.^{-1}\right)$ can be obtained as:

$$
R_{s}=(a+b \cdot n / N) R_{a}
$$

Where $n$ is actual sunshine duration (hour), $N$ is maximum possible sunshine duration (hour), $n / N$ is relative sunshine duration, $a$ and $b$ are parameters.

\subsubsection{Hargreaves-Samani model}

Hargreaves and Samani firstly used the diurnal temperature range (DTR $=T_{\max }-T_{\min }$ ) to estimate solar radiation as follows:

$$
R_{s}=K r\left(T_{\max }-T_{\min }\right)^{0.5} R_{a}
$$

Where $T_{\max }$ and $T_{\min }$ are the daily maximum and minimum air temperature $\left({ }^{\circ} \mathrm{C}\right), \mathrm{Kr}$ is an empirical coefficient.

\subsubsection{Bristow-Campbell model}

Bristow-Campbell model proposed by Bristow and Campbell is another method for estimating solar radiation using DTR as following:

$$
R_{s}=A\left[1-\exp \left(-B \Delta T^{c}\right)\right] R_{a}
$$

Where $\Delta T=T_{\max }-T_{\min }, A, B, C$ are empirical coefficients which should be calibrated first.

\subsubsection{Model calibration and performance indicators}

The Ordinary Least Square (OLS) method is used to calibrate the parameters $a$ and $b$ for Ångström-Prescott model and the parameter $\mathrm{Kr}$ for Hargreaves-Samani model by minimizing the sums of the squares of deviation between estimated and observed values as following:

$$
Z=\sum_{i=0}^{m}\left[\hat{y}_{i}-y_{i}\right]^{2}=\min
$$

Where $\hat{y}$ is the best fit function; $y$ is the dependent variables; $m$ is data length.

The Nonlinear Least Square (NLS) method is used to calibrate the parameters $A, B$ and $C$ for Bristow-Campbell model by minimizing the weighted squares of the errors between observed and estimated values. This scalar-valued goodness-of-fit measure is called the chi-squared error criterion $\chi^{2}$ as follows:

$$
\chi^{2}(p)=y^{T} W y / 2-y^{T} W \hat{y}+\hat{y}^{T} W \hat{y} / 2
$$

Where $W$ is the weighting matrix, $y$ is the dependent variables, $\hat{y}$ is the fit function, $y^{T}$ and $\hat{y}^{T}$ are the transpose of $y$ and $\hat{y}$, respectively, $p$ is parameters. When the fit function $\hat{y}$ is nonlinear with the parameters $p$, the minimization of $\chi^{2}$ with respect to the parameters must be carried out iteratively. The goal of each iteration is to find a perturbation $h$ to the parameters $p$ that reduces $\chi^{2}$.

In order to test the performances of the three models above, correlation coefficient $(r)$ and root mean-square error (RMSE) are used by comparing the simulated and observed daily solar radiation. The RMSE value is closer to zero and $r$ value closer to 1.0 , the better the model performs.

\section{Results and discussions}

\subsection{Calibration for the three models}

Firstly, 94 stations with the measured solar radiation during the past years are used to calibrate the parameters $a$ and $b$ in the A-P model, $K r$ in the H$\mathrm{S}$ model using OLS method and $A, B$ and $C$ in the B-C model using NLS method. Figure 2 shows the distributions of the parameters in the three models.

The results show that the A-P model parameters $a$ in Figure 2(a) and $b$ in Figure 2(b) range from 0.13 to 0.30 with a mean value of 0.20 and range from 0.47 to 0.68 with a mean value of 0.55 , respectively. The values of $a$ are generally higher in the NA and TP zones. And the values of parameter $b$ are relatively higher in the southern part of the EM zone and the TP zone.

The value of $\mathrm{Kr}$ in Figure 2(c) in the H-S model is about 0.11-0.18 with an average value of 0.15 , which is relative higher in the NA, TP and north part of EM zones.
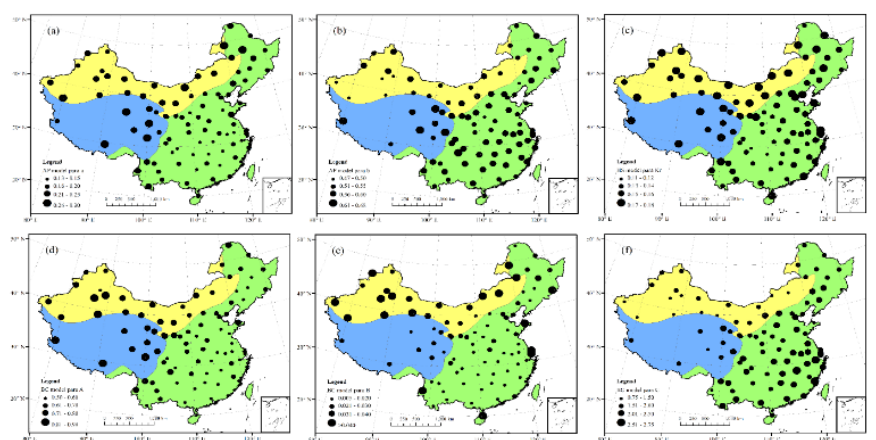

The value of parameter $A$ in Figure 2(d) in the B-C model varies from 0.50 to 0.88 with a mean value of 0.65 in China. The distribution of $A$ is quite similar with that of parameter $a$ in the A-P model. The parameter $B$ in Figure 2(e) in the B-C model is about 0.005-0.04 in most sites in the EM and TP zones and the value is relative higher in the NA zone. The distribution of parameter $C$ in Figure 2(f) varying between 0.75 and 2.75 in the B-C model shows a relative high value in the EM zone, especially in the southeastern of China; while in the other two regions that is mostly lower than 2.00 .

Figure 2 Distribution of the model parameters: parameters a (a) and $b$ (b) in A-P model, parameter $\mathrm{Kr}(\mathrm{c})$ in H-S model, parameters A (d), B (e) and $\mathrm{C}$ (f) in B-C model in different argo-climatic zones

The performances by comparing the measured and estimated daily solar 
radiation in the 94 sites in different agro-climate zones are shown in Table 1. The calibrated A-P, H-S and B-C models all perform well in daily solar radiation estimation with the values of $r$ which are about $0.94,0.81$ and 0.82 respectively and the values of $R M S E$ are about $2.40 \mathrm{MJm}^{-2}$ day $^{-1}$, $4.38 \mathrm{MJm}^{-2}$ day $^{-1}$ and $4.14 \mathrm{MJm}^{-2} \mathrm{day}^{-1}$ respectively. These results indicate that the A-P model perform relative better than the other two models, which is similar to the previous studies that the model based on sunshine duration is more accurate than other meteorological variable-based models such as temperature based models [20].

Table 1 The performances of the A-P, H-S and B-C models on daily solar radiation estimation in China

\begin{tabular}{lllllll}
\hline \multirow{2}{*}{ Region } & \multicolumn{2}{l}{ A-P model } & \multicolumn{2}{l}{ H-S model } & \multicolumn{2}{c}{ B-C model } \\
\cline { 2 - 7 } & $r$ & $R M S E$ & $r$ & $R M S E$ & $r$ & $R M S E$ \\
\hline EM & 0.94 & 2.50 & 0.79 & 4.56 & 0.81 & 4.18 \\
NA & 0.96 & 2.06 & 0.86 & 3.95 & 0.85 & 4.08 \\
TP & 0.92 & 2.57 & 0.78 & 4.17 & 0.80 & 4.02 \\
Average & 0.94 & 2.40 & 0.81 & 4.38 & 0.82 & 4.14 \\
\hline
\end{tabular}

The unit of RMSE is $\mathrm{MJm}^{-2} \mathrm{day}^{-1}$.

It's should also be mentioned that although the A-P model performs better than the H-S and B-C models, yet the two temperature-based models are still necessary for the limited data of sunshine duration for mapping spatiotemporal distributions of solar radiation. This is why the H-S and B$\mathrm{C}$ models are calibrated and used in this study.

\subsection{Spatiotemporal characterization of solar radiation}

\subsubsection{Spatial characteristics of solar radiation}

To analyse the spatiotemporal characteristics of annual and seasonal radiation in China, the coefficients in other stations which have no observed solar radiation are firstly estimated by Ordinary Kriging interpolation method using the calibrated parameters. Then the solar radiations are estimated based on the three models as described before. The spatial distributions of annual and seasonal solar radiation are shown in Figure 3 and Table 2.

At annual timescale, the solar radiations are about 8.67 21.20 $\mathrm{MJm}^{-2} \mathrm{day}^{-}$ 1, 8.70 21.06 $\mathrm{MJm}^{-2} \mathrm{day}^{-1}$ and $4.75 \sim 23.85 \mathrm{MJm}^{-2} \mathrm{day}^{-1}$ by the A-P, H-S and B-C models, as shown in Figure 3(a), (b) and (c) respectively. All three models show a similar spatial distribution that the annual solar radiation higher in the NA and TP zones than in the EM zone. In the EM zone, solar radiation is higher in the southwestern part and the lower in the southern part of the region. In the TP zone, the spatial distributions by the three models are with some difference. The annual solar radiation is higher in the southern part by the A-P model, which is higher in the southwestern part by the H-S and B-C models. In the NA zone, the distributions of annual solar radiation are similar to each other by the three models, which is lower in the northern part and higher in the southern part of this region.

The spatial distributions of solar radiation over seasonal times are different with that of annual solar radiation and the distributions are various from different seasons. The solar radiation in spring are about 9.07 24.93 $\mathrm{MJm}^{-2} \mathrm{day}^{-1}, 10.54 \sim 24.49 \mathrm{MJm}^{-2} \mathrm{day}^{-1}$ and $6.44 \sim 28.32 \mathrm{MJm}^{-}$ ${ }^{2}$ day $^{-1}$ by the A-P, H-S and B-C models, as shown in Figure 3(d), (e) and (f) respectively. The solar radiation in spring is also higher in the NA and TP zones than in the EM zone. In the EM zone, the solar radiation in the southern part except for the southwestern part of the region is lower than that in the northern part. In the TP zone, the distributions of solar radiation in spring show an increase trend from north to south based on the A-P and B-C model, while the increase trend from east to west is detected based on $\mathrm{H}-\mathrm{S}$ model. In the NA zone, the solar radiation in spring is relative higher in the southern and eastern part of this region.

The summer solar radiation as shown in Figure 3(g), (h) and (i) based on the A-P, H-S and B-C models are about 12.65 25.92 $\mathrm{MJm}^{-2} \mathrm{day}^{-1}$, 10.67 26.55 $\mathrm{MJm}^{-2} \mathrm{day}^{-1}$ and 5.22 29.94 $\mathrm{MJm}^{-2} \mathrm{day}^{-1}$, respectively. The solar radiation is higher in the NA and TP zones than in the EM zone. In the EM zone, the summer solar radiation is higher in the northern part than that in the southern part of China. In the TP zone, the solar radiation in summer is higher in the western part by the three models with a little difference of distribution. In the NA zone, the solar radiation in summer is higher in the central part by the A-P model and is higher in the western part by $\mathrm{H}-\mathrm{S}$ and $\mathrm{B}-\mathrm{C}$ models.

The solar radiation in autumn as shown in Figure 3(j), (k) and (l) based on the A-P, H-S and B-C models are about 7.05 19.80 $\mathrm{MJm}^{-2}$ day $^{-1}, 7.45 \sim 18.69$
$\mathrm{MJm}^{-2} \mathrm{day}^{-1}$ and 4.01 21.41 $\mathrm{MJm}^{-2} \mathrm{day}^{-1}$, respectively. The results show a higher autumn solar radiation in the TP zone than the other two regions. In the EM zone, a low solar radiation occurs in the southwestern part and in the northernmost part. In the TP zone, solar radiation decreases from southwest to northeast. In the NA zone, solar radiation decreases from south to north.

The solar radiation in winter are about 4.31 16.92 $\mathrm{MJm}^{-2} \mathrm{day}^{-1}$, 4.77 16.64 $\mathrm{MJm}^{-2} \mathrm{day}^{-1}$ and $3.13 \sim 18.62 \mathrm{MJm}^{-2}$ day $^{-1}$ based on the A-P, H-S and B-C models as shown in Figure 3(m), (n) and (o), respectively. We can see that the distribution of winter solar radiation is similar with that of autumn solar radiation in the three zones with a little difference that a higher winter solar radiation occurs in the southwestern part of China.

Generally, the mapping results by the three models show similar distributions with little differences at local areas. The solar radiation in the EM zone is lowest at annual and seasonal timescales. The solar radiation in the TP zone is most abundant at annual scale and in spring, autumn and winter. In summer, the solar radiation is highest in the NA zone.

\subsubsection{Trend analysis of solar radiation}

Based on the Mann-Kendall test [21], the changing trends of annual and seasonal solar radiation are test for the 756 meteorological stations in China. The results of the trend test on annual and seasonal solar radiation by the A-P, H-S and B-C models in the three agro-climate zones are shown in Table 2, respectively.

The results show that annual solar radiation decreases significantly in $58.0 \%$ of the sites in the EM zones, while in the other two zones significantly decreases are showed in fewer sites about $35.1 \%$ and $28.2 \%$ for the NA and TP zones, respectively based on the A-P model. Based on the H-S and B-C model, annual solar radiation decreases significantly in the EM zone with $43.4 \%$ and $42.8 \%$ of the sites respectively, and more sites in the NA zone show decrease trends with $62.6 \%$ and $64.1 \%$ of the sites respectively. In the TP zone, about $37.3 \%$ and $39.1 \%$ sites respectively show significant decrease trend. From Table 2, we find that the mean solar radiation in the EM and the NA zone show significant decrease trend at the significance level of 0.01 , while that shows no significant trends in the Tibetan Plateau frigid zone based on the A-P and B-C model.

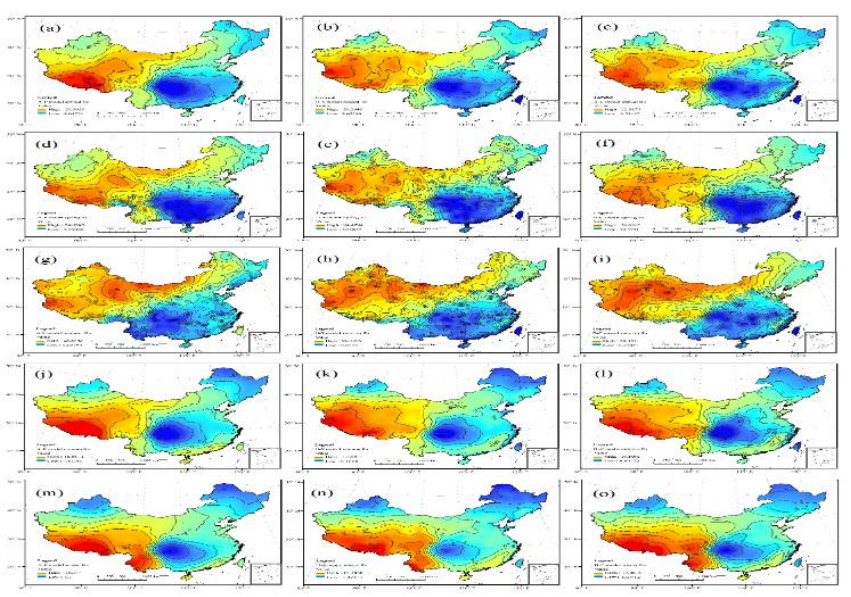

Figure 3 Spatial distribution of annual (the first row) and seasonal (from spring to winter: the second row to the fifth row) solar radiation in China based on A-P (the first column), H-S (the second column) and B-C (the third column) models

At the seasonal timescale, solar radiation shows different changing trends in different seasons. In spring, the changing trends are similar based on the three methods showing significant decrease trends about $27.8 \%$, $32.3 \%$ and $27.8 \%$ of the sites in the EM zone, respectively. In the TP zone, about $36.4 \%$ sites show significant decrease trends based on the H-S and B-C models, while less sites about $18.2 \%$ show decrease trends. In the NA zone, about $17.6 \%, 62.6 \%$ and $54.2 \%$ of the sites show significant decrease trends based on the A-P, H-S and B-C models. In summer, the results show significant decrease trends in about $56.8 \%$ sites of the EM zone and $29.0 \%$ sites in the NA zone and $21.8 \%$ sites in the TP zone based on the A-P model. And the significant decrease trends are shown in $40.7 \%$ and $37.9 \%$ of the sites in the EM zone and $51.9 \%$ and $43.5 \%$ in the NA and $22.7 \%$ in the TP zone based on the H-S and B-C models. In autumn, the results show that significant decrease trends mainly occur at the sites in the NA zone about $39.7 \%, 44.3 \%$ and $43.5 \%$ based on the three models. The sites are about 
$37.9 \%, 20.2 \%$ and $16.5 \%$ in the EM zone and that about $15 \%$ in the TP zone. In winter, the results show significant decreases trends are mostly in the EM zone about $37.9 \%, 41.2 \%$ and $34.0 \%$ of the sites and the NA zone about $53.4 \%, 67.9 \%$ and $67.2 \%$ based on the three models, respectively. By averaging the solar radiation in the different agro-climatic zones, the mean solar radiation decreases significantly in all the seasons in the NA zone. The solar radiation decreases significantly in summer and winter by the three models and decreases significantly in spring and autumn by the A-P model, while in the TP zone solar radiation shows no significant changing trends except for winter by the A-P model and summer by the $\mathrm{H}$ $S$ model.

From the results above, we find that solar radiation changes not significantly in the TP zone, while it changes significantly in the NA zone in all the seasons. In the EM zone, solar radiation decreases significantly in summer and winter and annual scale. We can also see that the temporal distributions show some differences and the trends are not consistent based on the three models. The possible reasons may be due to the differences of the changing trends of sunshine duration and temperature.

Table 2 The annual and seasonal solar radiation in China and the changing trends based on Mann-Kendall test

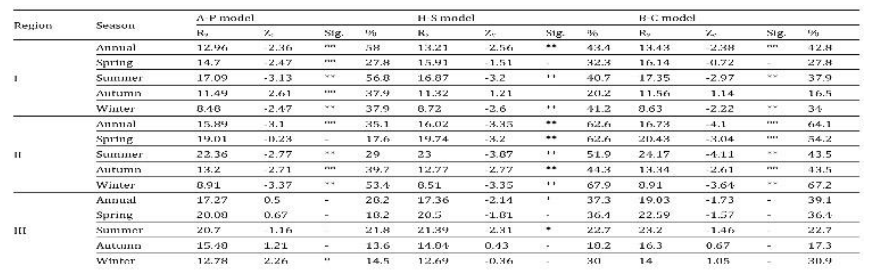

\subsubsection{Analysis of solar radiation in China}

By averaging the annual and seasonal solar radiations of the 756 sites in China, the mean values are shown in Table 3. The values of average annual solar radiation are $14.09 \mathrm{MJm}^{-2} \mathrm{day}^{-1}, 14.30 \mathrm{MJm}^{-2}$ day $^{-1}$ and $14.80 \mathrm{MJm}$ ${ }^{2}$ day $^{-1}$ based on the A-P, H-S and B-C models, respectively. The mean values of the seasonal solar radiation are $16.23 \mathrm{MJm}^{-2} \mathrm{day}^{-1}, 17.24 \mathrm{MJm}^{-2} \mathrm{day}^{-1}$ and 17.81 MJm${ }^{-2}$ day $^{-1}$ in spring, $18.55 \mathrm{MJm}^{-2}$ day $^{-1}, 18.61 \mathrm{MJm}^{-2}$ day $^{-1}$ and 19.40 $\mathrm{MJm}^{-2}$ day $^{-1}$ in summer, $12.35 \mathrm{MJm}^{-2} \mathrm{day}^{-1}, 12.07 \mathrm{MJm}^{-2}$ day $^{-1}$ and $12.54 \mathrm{MJm}^{-}$ ${ }^{2}$ day $^{-1}$ in autumn, $9.15 \mathrm{MJm}^{-2} \mathrm{day}^{-1}, 9.23 \mathrm{MJm}^{-2}$ day $^{-1}$ and $9.24 \mathrm{MJm}^{-2} \mathrm{day}^{-1}$ in winter based on the three models, respectively. We can see that the estimated annual and seasonal solar radiation is higher based on the B-C model comparing to the other two models.

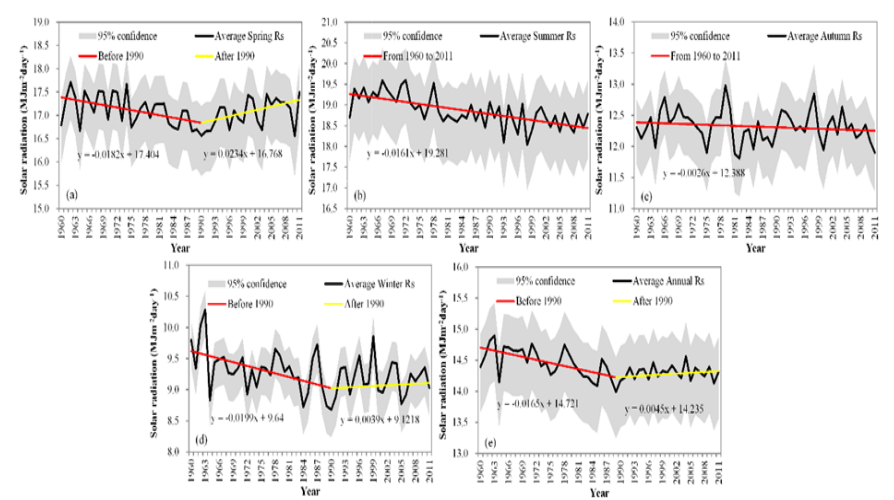

The Mann-Kendall test is used to test the changing trends for the whole solar radiation as shown in Table 3 . From the results we can see all the three models showing a significant

decrease trend for annual and summer solar radiation in the past years at the significance level of 0.01 , while the changing trends are not significant for the spring solar radiation. The changing trends for the solar radiation in autumn and winter are different by the three models. Only the A-P model indicates a significant decrease trend in autumn solar radiation and the H-S model shows a significant decrease trend in winter solar radiation at the significance level of 0.5 .

To better understand the changing trends of the solar radiation in the past years, the phenomenon of "From diming to brightening" after 1990s are also investigated in this study as shown in Figure 4. From the results, we can see annual solar radiation, solar radiation in spring and winter indicate the phenomenon of "From diming to brightening". Moreover, the brightening is more significant in spring. The increase rate is about 0.0234 $\mathrm{MJm}^{-2}$ day $^{-1}$ per year, while in winter the solar radiation increases by $0.0039 \mathrm{MJm}^{-2} \mathrm{day}^{-1}$ per year and the annual solar radiation increases by
$0.0045 \mathrm{MJm}^{-2}$ day $^{-1}$ per year after 1990 . But in summer the solar radiation shows a continuous decrease trends by $0.016 \mathrm{MJm}^{-2}$ day $^{-1}$ per year, while the decrease trend is very slight in autumn by $0.0026 \mathrm{MJm}^{-2} \mathrm{day}^{-1}$ per year from 1960 to 2011.

Table 3 The average solar radiation in China and changing trends based on Mann-Kendall test

\begin{tabular}{|c|c|c|c|c|c|c|c|c|c|}
\hline & \multicolumn{3}{|c|}{ A-P model } & \multicolumn{3}{|c|}{ H-S model } & \multicolumn{3}{|c|}{$\mathrm{B}-\mathrm{C}$ model } \\
\hline & $\mathrm{R}_{\mathrm{s}}$ & $\mathrm{Z}_{\mathrm{c}}$ & Sig. & $\mathrm{R}_{\mathrm{s}}$ & $\mathrm{Z}_{\mathrm{c}}$ & Sig. & $\mathrm{R}_{\mathrm{s}}$ & $\mathrm{Z}_{\mathrm{c}}$ & Sig. \\
\hline Annual & 14.09 & -2.85 & $* *$ & 14.30 & -2.74 & $* *$ & 14.80 & -2.45 & $* *$ \\
\hline Spring & 16.23 & -1.89 & - & 17.24 & -1.93 & - & 17.81 & -0.96 & - \\
\hline Summer & 18.55 & -3.08 & $* *$ & 18.61 & -3.29 & $* *$ & 19.40 & -3.32 & $* *$ \\
\hline Autumn & 12.35 & -2.06 & $*$ & 12.07 & -0.90 & - & 12.54 & -0.59 & - \\
\hline Winter & 9.15 & -1.95 & - & 9.23 & -2.22 & $*$ & 9.42 & -1.85 & - \\
\hline
\end{tabular}

Figure 4 Changing trends of spring (a), summer (b), autumn (c), winter (d) and annual (e) solar radiation for the whole China

\section{Conclusions}

The Ångström-Prescott, Hargreaves-Samani and Bristow-Campbell are calibrated and validated and then used for the spatiotemporal analysis of solar radiation at annual and seasonal timescales. The calibration results show that all the three models perform well in the three different agroclimatic regions. The spatial distributions show that the annual and seasonal solar radiation in the TP and the NA zones are higher than that in the EM zone. The temporal distributions show that solar radiation changes are various at annual and seasonal timescales. The annual solar radiation decreases significantly in the EM and NA zone. The solar radiation decreases in most of the season in the NA zone. The decrease trends are only significantly in spring and autumn in the EM zone, while the trends are not significant in the TP zone based. Furthermore, "From diming to brightening" is investigated at different timescales in China. "From diming to brightening" occurs in winter, annual and particularly in spring radiation changes, while in summer solar radiation shows a continuous decrease trend and a slight decrease trend is detected in autumn solar radiation.

The parameters in the stations without measured solar radiation are interpolated using the calibrated parameters in the solar stations based on Ordinary Kriging method, which will bring uncertainties to the mapping results. And the parameterization for the empirical models is still need to be conducted in further studies.

\section{Acknowledgements}

This study was supported by CISPDR Independent Innovation Project (CX2013Z12, CX2013Z11) and "the Fundamental Research Funds for the Central Universities", South-Central University for Nationalities (CZQ15004).

\section{References}

[1] M. Wild et al., "From Dimming to Brightening: Decadal Changes in Solar Radiation at Earth's Surface," Science (80-. )., vol. 308, no. 5723, pp. 847-850, 2005.

[2] J. Ye, F. Li, G. Sun, and A. Guo, "Solar dimming and its impact on estimating solar radiation from diurnal temperature range in China, 1961 2007," Theor. Appl. Climatol., vol. 101, no. 1, pp. 137-142, 2010.

[3] E. L. Maxwell, "METSTAT - The solar radiation model used in the production of the national solar radiation data base (NSRDB)," Sol. Energy, vol. 62 , no. 4 , pp. 263-279, 1998.

[4] 0. Şenkal, "Modeling of solar radiation using remote sensing and artificial neural network in Turkey," Energy, vol. 35, no. 12, pp. 4795$4801,2010$.

[5] D. S. S. Wilks and R. L. L. Wilby, "The weather generation game: a review of stochastic weather models," Prog. Phys. Geogr., vol. 23, no. 3, pp. 329-357, 1999.

[6] G. H. Hargreaves, Z. A. Samani, and S. Z. A. Hargreaves G.H., "Estimating potential evapotranspiration.," J. Irrig. Drain. Div. - ASCE, vol. 108, pp. 225-230, 1982. 
[7] J.-L. Chen, H.-B. Liu, W. Wu, and D.-T. Xie, "Estimation of monthly solar radiation from measured temperatures using support vector machines - A case study," Renew. Energy, vol. 36, no. 1, pp. 413-420, 2011.

[8] J.-L. Chen, G.-S. Li, "Estimation of monthly average daily solar radiation from measured meteorological data in Yangtze River Basin in China , " Int J Climatol, vol. 33, no.2, pp.487-498, 2013

[9] J. A. Prescott, "Evaporation from water surface in relation to solar radiation," Transactions of the Royal Society of South Australia, vol. 64, pp. 114-118, 1940.

[10] K. L. Bristow and G. S. Campbell, "On the relationship between incoming solar radiation and daily maximum and minimum temperature," Agric. For. Meteorol., vol. 31, no. 2, pp. 159-166, 1984.

[11] J. C. Ododo, A. T. Sulaiman, J. Aidan, M. M. Yuguda, and F. A. Ogbu, "The importance of maximum air temperature in the parameterisation of solar radiation in Nigeria," Renew. Energy, vol. 6, no. 7, pp. 751-763, 1995.

[12] K. Ulgen and A. Hepbasli, "Solar radiation models. Part 2: Comparison and developing new models," Energy Sources, vol. 26, no. 5, pp. 521-530, 2004.

[13] M. . Iziomon and H. Mayer, "Assessment of some global solar radiation parameterizations," J. Atmos. Solar-Terrestrial Phys., vol. 64, no. 15, pp. 1631-1643, 2002.
[14] X. Liu et al., "Calibration of the Ångström-Prescott coefficients $(\mathrm{a}, \mathrm{b})$ under different time scales and their impacts in estimating global solar radiation in the Yellow River basin," Agric. For. Meteorol., vol. 149, no. 3-4, pp. 697-710, 2009 .

[15] D. L. Liu and B. J. Scott, "Estimation of solar radiation in Australia from rainfall and temperature observations," Agric. For Meteorol., vol. 106, no. 1, pp. 41-59, 2001.

[16] R. T. Pinker, B. Zhang, and E. G. Dutton, "Do satellites detect trends in surface solar radiation?," Science, vol. 308, no. 5723, pp. 850-854, 2005.

[17] X. A. Xia, P. C. Wang, H. B. Chen, and F. Liang, "Analyis of downwelling surface solar radiation in China from National Centers for Environmental Prediction reanalysis, satellite estimates, and surface observations," J. Geophys. Res. Atmos., vol. 111, no. 9, 2006.

[18] W. J. Tang, K. Yang, J. Qin, C. C. K. Cheng, and J. He, "Solar radiation trend across China in recent decades: A revisit with qualitycontrolled data," Atmos. Chem. Phys., vol. 11, no. 1, pp. 393-406, 2011.

[19] S. Pohl, P. Marsh, and A. Pietroniro, "Spatial-temporal variability in solar radiation during spring snowmelt," Nord. Hydrol., vol. 37, no. Iqbal 1983, pp. 1-19, 2006.

[20] M. Trnka, Z. Žalud, J. Eitzinger, and M. Dubrovský, "Global solar radiation in Central European lowlands estimated by various empirical formulae," Agric. For. Meteorol., vol. 131, no. 1-2, pp. 54-76, 2005.

[21] D. H. Burn and M. A. Hag Elnur, "Detection of hydrologic trends and variability," J. Hydrol., vol. 255, no. 1-4, pp. 107-122, 2002. 